\title{
Cegos e Aprendizagem de Genética em Sala de Aula: Percepçóes de Professores e Alunos ${ }^{1}$

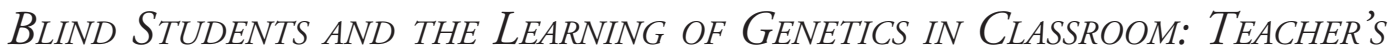 AND STUDENT'S PERCEPTIONS
}

\author{
Simone José Maciel da ROCHA ${ }^{2}$ \\ Edson Pereira da SILVA ${ }^{3}$
}

\begin{abstract}
RESUMO: percepçôes de professores e alunos de turmas mistas sobre o processo de ensino-aprendizagem de genética foram investigadas. As concepçōes dos professores foram obtidas a partir de questionários mistos e a dos alunos a partir de questionários baseados na escala de Likert. A análise dos resultados seguiu uma abordagem diferencial (sem grupo de comparação). Os dados foram categorizados seguindo os princípios da análise de conteúdo, seguido de um tratamento quali-quantitativo. Os resultados evidenciaram a forte influência de referências visuais nas percepçôes de professores e alunos videntes sobre as dificuldades enfrentadas na aprendizagem de genética. Embora alunos videntes e professores reconheçam que as imagens utilizadas nas aulas de genética sejam recursos facilitadores da aprendizagem de conceitos abstratos, continuam apresentando dificuldades a despeito do uso de estratégias visuais. Por outro lado, os alunos cegos sinalizaram os prejuízos decorrentes do uso acrítico desses recursos, posto que, dificultam a apreensão dos conceitos. Assim, parece que o primado da visão cega a todos, impedindo a percepção de que para além do ver está o ato construtivo do conhecer e que, pessoas desprovidas dessa cegueira, o caso dos cegos, podem indicar caminhos diferentes daqueles pré-estabelecidos para a apreensão de conceitos não visuais.
\end{abstract}

PALAVRAS-CHAVE: Educação Especial. Inclusão. Deficiência visual.

\begin{abstract}
The perceptions of teachers and students (in classrooms with young people with and without blindness) about the teaching and learning of genetics were investigated through a semi-structured questionnaire for teachers and a Likert scale questionnaire for students. Data analysis followed a differential approach, without a comparison group. Data were categorized according to content analysis, followed by a qualitative and quantitative treatment. Results evidenced a strong influence of visual reference both for teachers' and typical students' perceptions about the difficulties in learning genetics. Although typical students and teachers recognize that images used in genetics classes are facilitating tools of abstract concepts, they still present difficulties despite the use of visual strategies. On the other hand, blind students pointed to the damages caused by the acritical use of these resources, as they hindered the learning of concepts. Thus, it seems that the primacy of visual reference blinds us all, blocking the perception that beyond seeing is the constructive act of knowing, and that people who cannot see may indicate different paths from the ones pre-established for learning non-visual concepts.
\end{abstract}

KEYWORDS: Special Education. Inclusion. Visual impairment.

\section{INTRODUÇ̃̃o}

A Educação Especial é uma modalidade da educação escolar que atravessa todos os níveis de ensino beneficiando pessoas com necessidades educacionais (BRASIL, 2008; FOGLI, 2012). A educação de pessoas com necessidades especiais está fundamentada na Declaração de Salamanca (BRASIL, 1994), documento base da educação inclusiva, que dispóe que a educa-

\footnotetext{
${ }^{1}$ http://dx.doi.org/10.1590/S1413-65382216000400009

${ }^{2}$ Mestranda do Curso de Mestrado Profissional em Diversidade e Inclusão. Laboratório de Genética Marinha e Evolução - Instituto de Biologia, Departamento de Biologia Marinha, Universidade Federal Fluminense. Niterói, RJ, Brasil. sijmaciel@gmail.com

${ }^{3}$ Docente do Departamento de Biologia Marinha da Universidade Federal Fluminense, Coordenador do Laboratório de Genética Marinha e Evolução - Instituto de Biologia, Departamento de Biologia Marinha, Instituto de Biologia, Universidade Federal Fluminense. Niterói, RJ, Brasil. gbmedson@vm.uff.br
} 
ção escolar deve ser oferecida a todos sem distinção, independente das limitaçóes, sejam elas de ordem cognitiva, física ou sensorial (GASPARETTO et al., 2012; LOPES; FABRIS, 2013; FIQUEIREDO; KATO, 2015).

No Brasil, o movimento de educação inclusiva foi apoiado pela Lei de Diretrizes e Bases da Educação Nacional n. 9394/96 (BRASIL, 1996; MAZZARINO; FALKENBACH; RISSI, 2011; CUNHA, 2013; REGIANI; MÓL, 2013), a qual expressa em seu Capítulo V, art. 58 , que a Educação Especial deve ser oferecida preferencialmente na rede regular de ensino, devendo ser oferecidos serviços de apoio específico, quando necessário. Em função disso, houve um aumento do número de pessoas com necessidades especiais nas escolas que, por sua vez, passaram a viver o desafio de garantir o acesso de todos ao currículo comum, necessitando, portanto, de práticas pedagógicas que levassem em consideração as dificuldades destas pessoas (SANTOS, 2011; FOGLI, 2012; PLETSCH, 2014).

Dados extraídos do INEP de 2013 (BRASIL, 2014) revelam que o número de matrículas de alunos com necessidades educacionais especiais incluídos em classe regular no Brasil aumentou no período de 2007 a 2013, passando de 306136 para 648921 de um total de 50042448 matrículas na educação básica, evidenciando, assim, a importância de se refletir sobre o ensino na perspectiva inclusiva. Para Glat e Blanco (2007), a educação inclusiva impóe um novo modelo de escola, no qual procedimentos geradores de discriminação são substituídos por aqueles que possibilitam a remoção das barreiras que impedem a aprendizagem.

As políticas educacionais de inclusão têm implicado na reestruturação de escolas de ensino regular com a formação de turmas mistas, nas quais aprendem juntos alunos com e sem necessidades especiais (BRASIL, 2001). Dentre as necessidades especiais presentes em turmas mistas se encontra a cegueira. Alunos com cegueira em classes inclusivas têm sido um grande desafio para professores das diversas disciplinas (LAPLANE; BATISTA, 2008).

Para Regiani e Mól (2013), a inclusão de alunos no sistema de ensino não requer somente intervenções de infraestrutura, mas, também, aquelas que promovam a superação das barreiras pedagógicas. Figueiredo e Kato (2015) sinalizam que alunos deficientes visuais encontram-se comprometidos na escolarização devido a múltiplos fatores, tais como, inadequação dos recursos didáticos, exclusão tecnológica, ausência de atividades experimentais adaptadas, formação inadequada do docente e forte apelo visual nas didáticas das diversas disciplinas.

Dentre as disciplinas regulares, presentes no currículo comum, encontra-se a Biologia, incorporada na disciplina de ciências no Ensino Fundamental e como disciplina independente no ensino médio. A Biologia é uma disciplina que recorre sistematicamente às imagens como estratégia pedagógica. Desta forma, é uma disciplina que pode oferecer grandes dificuldades para aprendizagem de pessoas cegas. Portanto, ensinar alunos com cegueira em turmas regulares tem sido um grande desafio para professores de Biologia que, ao longo de suas trajetórias profissionais recorreram, sempre, às imagens como instrumento para promover o ensino e a aprendizagem de conceitos (SANTOS; MANGA, 2009; CARDINALI; FERREIRA, 2010). Um exemplo da ênfase dada às imagens no ensino de Biologia são os livros didáticos desta disciplina, que usam muitas delas para facilitar a compreensão dos conceitos e, além disso, despertar o interesse dos alunos (PERALES; JIMÉNEZ, 2002; BARROS; CARNEIRO, 2005; HECK; HERMEL, 2014). 
Segundo Heck e Hermel (2014), as ilustrações são ferramentas que contribuem para a construção de imagens mentais favorecendo a aprendizagem significativa dos conceitos. Klautau-Guimarães et al. (2008) e Ferreira et al. (2013) afirmam que as imagens e os modelos didáticos são recursos que facilitam a compreensão de conceitos básicos pela sua visualização. Contudo, Batista (2005) faz uma advertência sobre a supervalorização das imagens para o processo de apreensão de conceitos. Segundo ela, a aprendizagem é um processo que depende da integração dos sistemas sensoriais e cognitivos, tais quais, atenção, pensamento e memória. Desta forma, a ênfase dada às imagens superestima o papel da visão na apreensão de conceitos. Mais que isso, segundo Barros e Carneiro (2005), existe, para alguns alunos, uma confusão entre o que são os elementos simbólicos e os dados reais. Por exemplo, é comum que os alunos tenham a concepção equivocada de que os genes estão codificados como letras no DNA. Assim, apesar dos recursos visuais serem ferramentas importantes para o ensino, o seu uso acrítico pode torná-los verdadeiros obstáculos para compreensão de alguns conceitos. No caso dos cegos, mais do que um obstáculo conceitual, a ênfase em recursos visuais se torna um obstáculo de fato para o aprendizado (BATISTA, 2005). Neste sentido, uma prática pedagógica apoiada nos padróes de ensino para pessoas videntes pode não ser o mais adequado para pessoas cegas.

Neste trabalho, pretende-se discutir o primado da visão no ensino de conceitos biológicos que não possuem existência real, concreta e que, portanto, não são acessíveis por meio da visão, como é o caso de muitos conceitos em genética (SOLHA; SILVA, 2004). Para tanto, as percepçóes de professores e alunos sobre a aprendizagem da genética em turmas mistas foram investigadas. As estratégias pedagógicas empregadas por professores para o ensino dos conceitos foram inventariadas e as suas percepçóes sobre as dificuldades enfrentadas no trabalho com turmas mistas analisadas. Além disso, a percepção dos alunos quanto às dificuldades relacionadas ao aprendizado da genética mendeliana foram verificadas tanto para alunos cegos quanto videntes.

\section{Método}

A presente pesquisa teve início após a autorização prévia dos representantes responsáveis pela instituição de ensino e dos sujeitos envolvidos na investigação através da aprovação concedida pelo Comitê de Ética em Pesquisa da instituição envolvida e pelo preenchimento dos Termos de Assentimento e Consentimento Livre e Esclarecido.

Os docentes e alunos investigados pertencem a um colégio público da rede federal de ensino da cidade do Rio de Janeiro. Os dados dos professores e alunos obtidos nessa pesquisa não representam a totalidade do colégio. Portanto, o grupo de professores e a turma foram previamente selecionados, tendo-se para isso os seguintes critérios de inclusão: os professores deveriam ser de Biologia e estar lotados no mesmo campus da turma a ser investigada; a turma deveria ser do $3^{\circ}$ ano do ensino médio, etapa na qual os conteúdos de Biologia averiguados são abordados neste colégio e deveria ser mista, ou seja, ser composta por um grupo de alunos videntes e cegos.

As concepçóes dos professores de Biologia sobre o ensino de conceitos de Biologia na perspectiva inclusiva foram obtidas através de questionário semiaberto. A escolha deste instrumento se deveu ao fato de que favorece a tabulação dos dados obtidos, a liberdade de resposta dos sujeitos e a coleta de um número maior de informaçóes, o que favorece a representatividade e fidelidade em relação ao tema pesquisado (GIL, 2008). 
As concepçôes dos alunos foram averiguadas a partir de questionários mistos, baseados na escala de Likert, escala de graduação com a indicação de graus de concordância ou discordância em relação a cada um dos enunciados (GIL, 2008).

A acessibilidade aos questionários, termos de assentimento e consentimento foi garantida aos alunos cegos através da disponibilização destes documentos nas versóes braile e digital. Os procedimentos com os alunos foram realizados no ambiente escolar, na própria sala de aula na qual os alunos já estavam habituados.

Para a análise dos resultados foi utilizada uma abordagem diferencial, na qual as concepções foram investigadas, dentro de uma população sem comparação com um grupo padrão (abordagem comparativa) que, no caso de estudos com cegos, é sempre os videntes (BATISTA, 2005).

Os dados sofreram tratamento quali-quantitativo e foram categorizados seguindo os princípios da análise de conteúdo de Bardin (1977). Inicialmente, os questionários passaram por uma leitura flutuante (ou geral), o que permitiu as primeiras impressóes. Posteriormente, uma leitura mais atenta possibilitou a reflexão sobre o conteúdo e a definição das unidades de registro que seriam consideradas, bem como a definição das categorias de acordo com o objetivo de estudo.

\section{Resultados}

\subsection{Os Professores}

Do total de 12 professores convidados para participar da pesquisa, 11 se dispuseram a responder o questionário (Tabela 1 ). Com relação a estes, existe uma diversidade de tempo em atividade na profissão. Há professores com pouco tempo de exercício (dois anos apenas, por exemplo) e, outros, com mais de 30 anos de atividade em sala de aula. Atuando como professores de Ciências Biológicas no colégio investigado, existem aqueles com apenas poucos meses na instituição e, outros, com mais de 20 anos na casa. A maioria dos professores já possui mestrado (Tabela 2) e são egressos de Universidades Públicas (Tabela 3).

Tabela 1 - Faixa etária dos professores participantes da pesquisa.

\begin{tabular}{|c|c|c|c|c|c|}
\hline \multirow{2}{*}{ Professores } & \multirow{2}{*}{$\mathbf{N}$} & \multirow{2}{*}{$\%$} & \multicolumn{3}{|c|}{ Idade } \\
\hline & & & Mínima & Máxima & Média \\
\hline Masculino & 7 & 63.64 & 32 & 57 & 44.5 \\
\hline Feminino & 4 & 36.36 & 28 & 51 & 39.5 \\
\hline Geral & 11 & 100 & 28 & 57 & 42.5 \\
\hline
\end{tabular}

Legenda: N=Número absoluto de professores

Fonte: elaboração própria

Tabela 2 - Nível de formação dos professores participantes da pesquisa.

\begin{tabular}{lll}
\hline Níveis & $\mathbf{N}$ & \% \\
\hline Graduação & 3 & 27.27 \\
Especialização & 1 & 9.09 \\
Mestrado & 6 & 54.55 \\
Doutorado & 1 & 9.09 \\
Total & 11 & 100 \\
\hline
\end{tabular}

Legenda: $\mathrm{N}$ = Número absoluto de professores

Fonte: elaboração própria 
Tabela 3 - Origem institucional dos professores.

\begin{tabular}{lcc}
\hline Universidade & $\mathbf{N}$ & $\mathbf{\%}$ \\
\hline Pública & 7 & 63.64 \\
Particular & 4 & 36.36 \\
Total & 11 & 100 \\
\hline
\end{tabular}

Legenda: $\mathrm{N}$ = Número absoluto de professores

Fonte: elaboração própria

Quando perguntados se as respectivas formaçóes acadêmicas contemplaram a Educação Especial/Inclusiva, a grande maioria (81.8\%) dos professores respondeu que não teve uma disciplina específica nesta área ao longo da formação acadêmica. Uma professora informou que possuía uma especialização em Educação Especial e, outra, que tinha tido uma disciplina na graduação na qual alguns aspectos teóricos e práticos da Educação Especial/inclusiva tinham sido abordados. A grande maioria dos professores (72.7\%) informou, também, não ter participado de eventos e/ou cursos de atualização profissional na área da inclusão. Entre os eventos citados por aqueles que tiveram alguma participação neste tipo de atividade estiveram encontros sobre neurobiologia, encontros científicos no próprio colégio e cursos de braile (também oferecido pelo colégio).

Sobre o que consideraram fundamental para que houvesse a inclusão de alunos com deficiência visual no ensino médio foi citada a necessidade de estrutura física (materiais de apoio adaptado e infra-estrutura institucional adequada), material humano (formação docente e dos demais profissionais da comunidade escolar, comprometimento dos professores, presença de profissionais especializados e atuação colaborativa entre alunos) e suporte pedagógico (atualização de metodologias, conteúdos e avaliações, reconfiguração dos serviços e dinâmica escolar e apoio logístico). Estes resultados estão resumidos na Tabela 4.

Tabela 4 - Fatores considerados relevantes pelos professores para que haja a efetiva inclusão de alunos com deficiência visual no ensino médio.

\begin{tabular}{lcc}
\hline \multicolumn{1}{c}{ Fatores } & N & \% \\
\hline Formação docente & 5 & 45.45 \\
Materiais de apoio adaptados & 4 & 36.36 \\
Comprometimento/esforço do professor & 3 & 27.27 \\
Profissional especializado & 3 & 27.27 \\
Infraestrutura institucional/apoio logístico & 3 & 27.27 \\
Atuação colaborativa entre alunos & 2 & 18.18 \\
Reconfiguraçáo dos serviços e da dinâmica & 2 & 18.18 \\
escolar/apoio logístico & 1 & 9.09 \\
Preparação de toda comunidade escolar & & \\
(Reflexão) sobre o fazer pedagógico (meto- & 1 & 9.09 \\
dologia, conteúdo e avaliaçóes) & & \\
\hline
\end{tabular}

Legenda: $\mathrm{N}$ = Número absoluto de professores

Fonte: elaboração própria 
Dos 11 professores, 8 (72.7\%) reconheceram que recebem apoio do Núcleo de Atendimento a Pessoas com Necessidades Específicas (NAPNE) que existe na escola e dois (18.2\%) não tiveram este apoio, porém justificaram o fato por não terem tido experiência com alunos com necessidades educacionais especiais ou por não terem interagido, ainda, com o setor. Um dos professores não respondeu a essa pergunta. Aqueles que relataram que receberam apoio do NAPNE entenderam que este era o setor responsável por oferecer serviços pedagógicos voltados para a inclusáo dos alunos com necessidades educacionais especiais. Foram identificadas como açóes específicas do NAPNE, o apoio pedagógico para o planejamento de estratégias junto aos alunos com necessidades especiais, as adaptaçóes e aplicação de materiais didáticos e de instrumentos de avaliação, a disponibilização de materiais táteis e de textos em braile, a atuação de um professor de Biologia no setor para complementar/aprofundar conteúdos desenvolvidos em sala de aula e a disponibilização de ledores durante as avaliaçóes.

Para atender as necessidades educacionais dos alunos com deficiência visual no ensino médio, os professores recorrem a diversos recursos pedagógicos, tendo maior destaque o uso de modelos didáticos táteis (Tabela 5).

Tabela 5 - Recursos utilizados pelos professores de Biologia em turmas mistas com deficiente visual.

\begin{tabular}{lcc}
\hline \multicolumn{1}{c}{ Recursos } & N & \% \\
\hline Modelos didáticos táteis & 6 & 54.54 \\
Material produzido e disponibilizado pelo NAPNE & 3 & 27.27 \\
Descriçóes detalhadas & 2 & 18.18 \\
Material digital & 1 & 9.09 \\
Analogias & 1 & 9.09 \\
Escritas sistematizadas no caderno & 1 & 9.09 \\
Placa de borracha & 1 & 9.09 \\
Gravação de voz & 1 & 9.09 \\
Adaptação tátil de esquemas & 1 & 9.09 \\
Oralização de pontos específicos & 1 & 9.09 \\
Material ampliado & 1 & 9.09 \\
\hline
\end{tabular}

Legenda: $\mathrm{N}$ = Número absoluto de professores

Fonte: elaboração própria

A maioria dos professores (63.63\%) apontou que as Leis de Mendel são aquilo com que os alunos apresentam maior dificuldade de aprendizagem (Tabela 6). 
Tabela 6 - Conceitos que impóem dificuldades aos alunos para a aprendizagem de genética na concepção dos professores.

\begin{tabular}{lcc}
\hline Conceitos & N & $\%$ \\
\hline Leis de Mendel & 7 & 63.63 \\
Ligaçáo gênica & 5 & 45.45 \\
Genética de populaçóes & 3 & 27.27 \\
Probabilidade & 2 & 18.18 \\
Citogenética & 1 & 9.09 \\
Meiose & 1 & 9.09 \\
Gametogênese & 1 & 9.09 \\
Genética molecular & 1 & 9.09 \\
Polialelia & 1 & 9.09 \\
Biotecnologia & 1 & 9.09 \\
Interação gênica (herança quantitativa) & 1 & 9.09 \\
Uso de heredogramas & 1 & 9.09 \\
\hline
\end{tabular}

Legenda: $\mathrm{N}$ = Número absoluto de professores

Fonte: elaboração própria

Em relação ao ensino, os conteúdos de genética que consideraram mais difíceis de serem abordados estão descritos na Tabela 7.

Tabela 7 - Conteúdos de genética considerados difíceis de serem ensinados pelos professores.

\begin{tabular}{lcc}
\hline Conceitos & N & $\%$ \\
\hline Interação gênica & 3 & 27.27 \\
Dominância gênica & 2 & 18.18 \\
Genética de populaçóes & 2 & 18.18 \\
2a Lei de Mendel & 2 & 18.18 \\
Meiose & 2 & 18.18 \\
Ligaçáo gênica & 1 & 9.09 \\
Cromossomos homólogos & 1 & 9.09 \\
Epistasia & 1 & 9.09 \\
Gametogênese & 1 & 9.09 \\
Genes alelos & 1 & 9.09 \\
Genética molecular & 1 & 9.09 \\
Herança sexual & 1 & 9.09 \\
Mutaçóes e reflexos na tradução & 1 & 9.09 \\
Polialelia & 1 & 9.09 \\
Probabilidade condicional & 1 & 9.09 \\
Quadro de Punnet & 1 & 9.09 \\
Teorema de Hardy-Weimberg para DV & 1 & 9.09 \\
\hline
\end{tabular}

Legenda: $\mathrm{N}$ = Número absoluto de professores

Fonte: elaboração própria

Os recursos considerados, pelos professores, como fundamentais para o processo de ensino-aprendizagem de genética estão listados na Tabela 8. 
Tabela 8 - Recursos considerados fundamentais para o ensino-aprendizagem de genética.

\begin{tabular}{lcc}
\hline Recursos & N & \% \\
\hline Quadros de cruzamentos & 4 & 36.36 \\
Materiais táteis & 3 & 27.27 \\
Recurso visual & 3 & 27.27 \\
Heredogramas & 2 & 18.18 \\
Exercícios & 2 & 18.18 \\
Animaçóes & 1 & 9.09 \\
Recursos matemático & 1 & 9.09 \\
Aproximação com o cotidiano & 1 & 9.09 \\
Dinâmicas & 1 & 9.09 \\
\hline
\end{tabular}

Legenda: $\mathrm{N}$ = Número absoluto de professores

Fonte: elaboração própria

Mais da metade dos professores (54.5\%) indicou que percebe diferenças na aprendizagem de genética entre alunos com e sem deficiência visual, pois, segundo eles, falar de genes exige capacidade de abstração. Os professores consideraram, ainda, que pessoas com deficiência visual apreendem o conhecimento de forma mais lenta. Atribuíram esta maior lentidão à impossibilidade de visualização das imagens utilizadas em aula. Além disso, acrescentaram que alunos com deficiência visual teriam rendimento menor devido a isto. Para os $18.2 \%$ que acreditam que não há diferenças de aprendizagem entre cegos e videntes, uma vez vencida a barreira entre indivíduo e conhecimento, não há mais diferenças na capacidade geral de aprendizagem. Esses professores consideraram, ainda, que a metodologia de ensino tem papel fundamental na superação das diferenças de aprendizagem entre cegos e videntes. Um professor não expressou sua opinião, uma vez que ainda não tinha tido a experiência de lecionar para alunos com deficiência visual.

Para aqueles professores que afirmaram que há diferenças de aprendizagem entre pessoas com e sem deficiência visual, foi solicitado que indicassem recursos que consideravam importantes para facilitar a aprendizagem destes alunos. Os resultados encontram-se na Tabela 9.

Tabela 9 - Fatores considerados importantes para o ensino-aprendizagem de genética para deficientes visuais.

\begin{tabular}{llc}
\hline \multicolumn{1}{c}{ Fatores } & N & \% \\
\hline Material didático tátil & 5 & 45.45 \\
Atendimento individualizado & 2 & 18.18 \\
Desenvolvimento de metodologia & 2 & 18.18 \\
Livro em braile & 1 & 9.09 \\
\hline
\end{tabular}

Legenda: $\mathrm{N}$ = Número absoluto de professores

Fonte: elaboração própria

\subsection{Os Alunos}

Dos 31 alunos, 25 aceitaram participar da pesquisa, sendo 23 alunos sem deficiência visual e dois cegos congênitos. Dos 25 alunos investigados, nove são do sexo masculino e 16 do sexo feminino, com idades entre 17 e 24 anos. Todos cursavam a $3^{\circ}$ ano do ensino médio. $\mathrm{O}$ 
Aluno Cego A (ACA), tinha 25 anos e era cego de nascença devido à atrofia do nervo óptico. $\mathrm{O}$ Aluno Cego $B$ (ACB) tinha 20 anos e sua cegueira era devida à degeneração da retina causada pela retinose pigmentar. ACB era atleta de goalball e futsal e cursava o $3^{\circ}$ ano pela segunda vez devido à reprovaçáo em ano anterior. Apesar dos alunos cegos terem recebido o questionário em versão impressa em braile e em versão digital (txt), solicitaram que o mesmo fosse lido e que as respostas fossem dadas oralmente. A pesquisadora leu o questionário, ao mesmo tempo, para os dois alunos e as respectivas respostas foram devidamente registradas. A maioria dos alunos sem deficiência visual (65.22\%) respondeu ter tido algum tipo de dificuldade no aprendizado de genética nas aulas de Biologia (Tabela 10).

Tabela 10 - Grau de dificuldade para a aprendizagem de genética em alunos sem deficiência visual.

\begin{tabular}{lcc}
\hline Grau de Dificuldade & N & \% \\
\hline Nunca/Raramente & 7 & 30.43 \\
Algumas vezes/Frequentemente/Sempre & 15 & 65.22 \\
Não respondeu & 1 & 4.35 \\
\hline
\end{tabular}

Legenda: $\mathrm{N}$ = Número absoluto de professores

Fonte: elaboração própria

As dificuldades apontadas foram a didática utilizada pelo professor, a pouca oferta de exercícios, o tempo limitado para o desenvolvimento dos conteúdos e a natureza abstrata dos conceitos genéticos. Contudo, a natureza abstrata dos dados foi apontada como dificuldade para metade dos respondentes, tendo, a outra metade, náo encontrado dificuldade nesta característica dos conteúdos de genética. $\mathrm{O}$ vocabulário complexo, o desconhecimento de conceitos considerados básicos e o uso da matemática para a resolução de problemas de genética foram considerados dificuldades por uma pequena parcela dos alunos (menos de $10 \%$ em todos os casos). Estes resultados estão registrados na Tabela 11. Um aluno considerou, ainda, que a troca de professores prejudicou o aprendizado de genética, contudo, como um fator contingencial, não foi considerado, embora esteja sendo registrado aqui. Quanto aos alunos cegos, ACA informou que teve dificuldades algumas vezes, ao contrário de ACB que respondeu que raramente teve alguma dificuldade no aprendizado de genética.

Os alunos cegos concordaram com os alunos videntes que a didática do professor era um fator relevante para o aprendizado dos conceitos de genética. Contudo, apontaram que o ensino baseado em figuras contribui, também, para os seus problemas de aprendizagem de genética. Para ACB, a matemática raramente é um problema, enquanto que para ACA ela é, frequentemente, a responsável pelas suas dificuldades. Esses dois alunos não reconheceram o vocabulário específico, o tempo limitado, o pouco número de exercícios e o desconhecimento de conceitos básicos como fatores para suas dificuldades de aprendizagem da genética. 
Tabela 11 - Fatores que dificultam a aprendizagem de genética em alunos sem deficiência visual.

\begin{tabular}{lcccccccc}
\hline \multirow{2}{*}{$\begin{array}{l}\text { Fatores dificultadores da } \\
\text { aprendizagem }\end{array}$} & $\begin{array}{c}\text { Nunca } \\
\text { Raramente }\end{array}$ & \multicolumn{2}{c}{$\begin{array}{c}\text { Algumas vezes } \\
\text { Frequentemente } \\
\text { Sempre }\end{array}$} & $\begin{array}{c}\text { Náo marcou } \\
\text { resposta }\end{array}$ & \multicolumn{2}{c}{ Total } \\
\cline { 2 - 9 } & $\mathbf{N}$ & $\%$ & $\mathbf{N}$ & $\%$ & $\mathbf{N}$ & $\%$ & $\mathbf{N}$ & $\%$ \\
\hline Didática do professor & 6 & 26.09 & 16 & 69.56 & 1 & 4.35 & 23 & 100 \\
Tempo limitado & 10 & 43.48 & 12 & 52.17 & 1 & 4.35 & 23 & 100 \\
Poucos exercícios & 10 & 43.48 & 12 & 52.17 & 1 & 4.35 & 23 & 100 \\
Conceitos abstratos & 11 & 47.83 & 11 & 47.83 & 1 & 4.35 & 23 & 100 \\
Vocabulário & 12 & 52.17 & 10 & 43.48 & 1 & 4.35 & 23 & 100 \\
Desconhecimento de concei- & 12 & 52.17 & 9 & 39.13 & 2 & 8.70 & 23 & 100 \\
tos básicos & 15 & 65.21 & 6 & 26.09 & 2 & 8.70 & 23 & 100 \\
Matemática & & & & & & &
\end{tabular}

Legenda: $\mathrm{N}$ = Número absoluto de professores

Fonte: elaboração própria

Quanto aos tipos de recursos didáticos mais utilizados pelos professores, de acordo com os alunos sem deficiência visual, estes eram o quadro branco e o Data Show. O livro didático foi identificado, em $43.5 \%$ das respostas, como sendo, também, um recurso explorado pelos professores (Tabela 12). Os alunos cegos concordaram com os demais quanto aos tipos de recursos didáticos usados pelos professores. Porém, eles responderam que os professores de Biologia costumavam usar em suas aulas, também, charges e quadrinhos.

Tabela 12 - Recursos utilizados pelos professores na concepção dos alunos sem deficiência visual.

\begin{tabular}{lcccccccc}
\hline Recursos & $\begin{array}{c}\text { Nunca } \\
\text { Raramente }\end{array}$ & \multicolumn{2}{c}{$\begin{array}{c}\text { Algumas vezes } \\
\text { Frequentemente } \\
\text { Sempre }\end{array}$} & $\begin{array}{c}\text { Náo marcou } \\
\text { resposta }\end{array}$ & Total \\
& $\mathbf{N}$ & $\%$ & $\mathbf{N}$ & $\%$ & $\mathbf{N}$ & $\%$ & $\mathbf{N}$ & $\%$ \\
\hline DVDs & 22 & 95.65 & 1 & 4.35 & - & - & 23 & 100 \\
Áudios & 22 & 95.65 & 1 & 4.35 & - & - & 23 & 100 \\
Charges e quadrinhos & 22 & 95.65 & 0 & 0 & 1 & 4.35 & 23 & 100 \\
Artigos/revistas/jornais & 20 & 86.96 & 3 & 13.04 & - & - & 23 & 100 \\
Computador & 16 & 69.56 & 6 & 26.09 & 1 & 4.35 & 23 & 100 \\
Datashow & 4 & 17.39 & 19 & 82.61 & - & - & 23 & 100 \\
Laboratório & 23 & 100 & 0 & 0 & - & - & 23 & 100 \\
Quadro branco & 3 & 13.04 & 19 & 82.61 & 1 & 4.35 & 23 & 100 \\
Livro didático & 13 & 56.52 & 10 & 43.48 & - & - & 23 & 100 \\
\hline
\end{tabular}

Legenda: $\mathrm{N}$ = Número absoluto de professores

Fonte: elaboração própria

Os alunos sem deficiência visual responderam (95.6\%) que para estudar utilizavam seus registros escritos das aulas, sendo, o livro didático, o segundo recurso mais utilizado (69.6\% das respostas), seguido das apostilas (47.8\%) e dos grupos de estudo (43.5\%). Um dos 
alunos informou, ainda, que usava a internet e videoaulas para auxiliar nos seus estudos (Tabela 13). Os alunos videntes raramente frequentavam o NAPNE, espaço que, pelos alunos cegos, era utilizado frequentemente. Os alunos cegos, assim como os videntes, costumavam usar seus registros escritos e apostilas para estudo. Contudo, se diferenciaram dos demais colegas por não utilizarem o livro didático, nem o estudo em grupo como recursos para auxiliar na sua aprendizagem dos conteúdos de genética.

Tabela 13 - Recursos utilizados pelos alunos sem deficiência visual para o estudo de genética.

\begin{tabular}{lcccccccc}
\hline \multicolumn{1}{c}{ Recursos } & \multicolumn{2}{c}{$\begin{array}{c}\text { Nunca } \\
\text { Raramente }\end{array}$} & \multicolumn{2}{c}{$\begin{array}{c}\text { Algumas vezes } \\
\text { Frequentemente } \\
\text { Sempre }\end{array}$} & \multicolumn{2}{c}{$\begin{array}{c}\text { Náo marcou } \\
\text { resposta }\end{array}$} & \multicolumn{2}{c}{ Total } \\
& $\mathbf{N}$ & $\mathbf{\%}$ & $\mathbf{N}$ & $\mathbf{0}$ & $\mathbf{N}$ & $\mathbf{0}$ & $\mathbf{N}$ & $\mathbf{\%}$ \\
\hline Registros escritos & 1 & 4.35 & 22 & 95.65 & - & - & 23 & 100 \\
Registros de Áudios & 21 & 91.30 & 2 & 8.70 & - & - & 23 & 100 \\
Livro didático & 7 & 30.43 & 16 & 69.57 & - & - & 23 & 100 \\
Apostilas & 12 & 52.17 & 11 & 47.83 & - & - & 23 & 100 \\
Grupo de estudo & 12 & 52.17 & 10 & 43.48 & 1 & 4.35 & 23 & 100 \\
NAPNE & 22 & 95.65 & 0 & - & 1 & 4.35 & 23 & 100 \\
\hline
\end{tabular}

Legenda: $\mathrm{N}$ = Número absoluto de professores

Fonte: elaboração própria

Dentre os 13 conceitos de genética listados no questionário, os alunos sem deficiência visual apontaram maiores dificuldades com os conteúdos relacionados a cromossomos homólogos, segregação independente e $1^{\text {a }}$ e $2^{\text {a }}$ Leis de Mendel (Tabela 14). Os alunos cegos relataram maiores dificuldades também com os conceitos relativos a cromossomos homólogos e segregação independente, mas, também, genótipo e fenótipo. Informaram, ainda, que, às vezes, tinham dúvidas quanto aos conceitos de homozigoto e heterozigoto.

Tabela 14 - Conceitos considerados difíceis pelos alunos sem deficiência visual.

\begin{tabular}{|c|c|c|c|c|c|c|}
\hline \multirow[t]{2}{*}{ Conceitos } & \multicolumn{2}{|c|}{$\begin{array}{c}\text { Nunca } \\
\text { Raramente }\end{array}$} & \multicolumn{2}{|c|}{$\begin{array}{l}\text { Algumas vezes } \\
\text { Frequentemente } \\
\text { Sempre }\end{array}$} & \multicolumn{2}{|c|}{ Total } \\
\hline & $\mathbf{N}$ & $\%$ & $\mathbf{N}$ & $\%$ & $\mathbf{N}$ & $\%$ \\
\hline Herança & 17 & 73.91 & 6 & 26.09 & 23 & 100 \\
\hline Fenótipo & 17 & 73.91 & 6 & 26.09 & 23 & 100 \\
\hline Genótipo & 16 & 69.57 & 7 & 30.43 & 23 & 100 \\
\hline Genes & 14 & 60.87 & 9 & 39.13 & 23 & 100 \\
\hline Alelos & 12 & 52.17 & 11 & 47.83 & 23 & 100 \\
\hline Dominante & 20 & 86.96 & 3 & 13.04 & 23 & 100 \\
\hline Recessivo & 20 & 86.96 & 3 & 13.04 & 23 & 100 \\
\hline Homozigoto & 19 & 82.61 & 4 & 17.39 & 23 & 100 \\
\hline Heterozigoto & 20 & 86.96 & 3 & 13.04 & 23 & 100 \\
\hline Cromossomos homólogos & 8 & 34.78 & 15 & 65.22 & 23 & 100 \\
\hline Segregação independente & 6 & 26.09 & 17 & 73.91 & 23 & 100 \\
\hline 1ª Lei de Mendel $^{\text {a }}$ & 11 & 47.83 & 12 & 52.17 & 23 & 100 \\
\hline 2a Lei de Mendel & 6 & 26.09 & 17 & 73.91 & 23 & 100 \\
\hline
\end{tabular}

Legenda: $\mathrm{N}$ = Número absoluto de professores

Fonte: elaboração própria 


\section{Discussáo}

A forte influência de recursos visuais no ensino de conceitos não acessíveis pelos sentidos indicou a necessidade de se compreender as concepçóes de professores e alunos sobre o ensino de genética em contexto educacional no qual pessoas cegas compartilham, com aqueles que veem, o mesmo espaço de aprendizagem.

O caso da genética chama atenção por tratar-se de uma área do conhecimento científico que tem sua origem em modelos racionais sem existência real (SOLHA; SILVA, 2004). Contudo, mesmo neste caso, o ensino é fortemente apoiado em recursos visuais. É interessante notar que tanto os alunos videntes quanto os professores com os quais se trabalhou nesta pesquisa sublinharam que as imagens são um recurso pedagógico importante para o ensino da genética em sala de aula. Ou seja, parece que para tentar superar as dificuldades do não ser possivel ver (as dificuldades de aprendizagem associadas à natureza abstrata dos conceitos genéticos), os professores de Biologia e os alunos videntes lançam mão de estratégias do ver (a representação de estruturas e fenômenos biológicos) (PERALES; JIMÉNEZ, 2002). Portanto, para aquilo que nấo se vê é ensinado com aquilo que se vê.

Sáo muitos os trabalhos que reforçam a necessidade da materialização no ensino de conceitos abstratos (CID; NETO, 2005; KLAUTAU-GUIMARÃES et al., 2008; MARÍN, 2013; MOURA et al., 2013; PETROVICH et al., 2014). Assim, professores recorrem a convenções gráficas próprias do universo dos videntes para representar, ilustrar, esquematizar e modelar conceitos, processos e fenômenos. No caso do ensino para cegos, alguns autores consideram, ainda, que o que não é apreendido pelos olhos, deve ser ensinado por meio de modelos táteis (LAPLANE; BATISTA, 2008; BATISTA, 2005; CARDINALI; FERREIRA, 2010) e que, para tanto, deve-se constituir um acervo contendo objetos, miniaturas e ampliaçóes, de forma a oferecer à criança cega, objetos variados que a auxiliem na construçáo dos diversos conceitos. Neste sentido, representaçôes visuais devem ser convertidas em representaçôes táteis.

Batista (2005), em sua pesquisa sobre a formação de conceitos em crianças cegas, critica trabalhos que usam como referencial básico o que não é próprio delas, isto é, a visão. Ela levanta questóes sobre o predomínio da visão no processo de elaboração conceitual e o papel da representaçáo no planejamento de recursos didáticos. A autora sublinha que o processo de conhecer não é equivalente ao processo de ver, embora esta equivalência seja, muitas vezes, assumida como verdadeira. Ou seja, assume-se que o ver é condição para o conhecer, ignorando-se que muitos dos conceitos científicos não têm possibilidade de observação visual. É interessante notar que os professores sinalizaram que, dentre os conceitos da genética que são de difícil ensino e aprendizagem, estão as Leis de Mendel. Ou seja, exatamente aquelas que dependem de objetos não visíveis para serem compreendidas (os fatores hereditários).

Pesquisas em ensino de Biologia têm indicado que a genética é considerada uma ciência difícil (TIDON; LEWONTIN, 2004; KLAUTAU-GUIMARÁES et al., 2008; PETROVICH et al., 2014; SILVA et al., 2014). Na literatura é possível identificar algumas destas dificuldades. Lewis e Wood-Robinson (2000) mencionam o complexo vocabulário e o uso de expressóes matemáticas como responsáveis por parte das dificuldades na aprendizagem dos conceitos genéticos. Barros e Carneiro (2005) indicam dificuldades relacionadas à interpretação das imagens presentes nos livro didáticos e citam como exemplo, as fases de divisão celu- 
lar (mitose e meiose) que necessitam da mediação do professor e conhecimentos prévios para que sejam compreendidas. Segundo Santos (2005), os conhecimentos adquiridos no cotidiano e conservados nas práticas sociais, como a noção de que o sangue esteja relacionado à transmissão das características hereditárias, dificultam a compreensão dos fenômenos da hereditariedade. Moura et al. (2013), sinalizam que a incompreensão de conceitos básicos de genética - alelo, gene, cromatina e cromossomo - prejudica o entendimento relacionado à herança genética.

Todas as dificuldades discutidas por estes autores são reais. Contudo, acredita-se, juntamente com Goldbach et al. (2009), Marín (2013), Moura et al. (2013) e Petrovich et al. (2014), que é a natureza abstrata dos conceitos genéticos que impóe o maior desafio a compreensão dos conceitos genéticos. Ou seja, fatores hereditários ou genes, que são a base de toda genética, seja ela clássica ou molecular, não estão sujeitos a visualização. Neste sentido, as estratégias usadas pelos cegos para apreensão destes conceitos talvez estejam sendo desperdiçadas em um ambiente dominado pelo primado da visão. Metade dos alunos videntes, por exemplo, identifica no caráter abstrato dos conceitos genéticos um problema para sua aprendizagem. Os cegos, no entanto, se referem à didática como sendo as suas maiores dificuldades.

Para boa parte dos professores com os quais se trabalhou aqui, os alunos cegos apresentam maior dificuldade de abstração que alunos videntes, requisito necessário para a apreensão dos conceitos genéticos. Os alunos cegos, no entanto, diferente dos videntes não viram no caráter abstrato dos conceitos genéticos um problema. É verdade que o número de alunos cegos participantes desta pesquisa é substancialmente menor do que aquele de videntes, o que limita a extensão de qualquer conclusão. Porém, é verdade, também, que a percepção dos professores é marcada pelo primado da visão.

Estudos focados em tão poucos indivíduos não são capazes de evidenciar o comportamento de todo um grupo (seja ele de cegos ou videntes). Mais que isso, a abordagem metodológica escolhida aqui foi aquela na qual as concepçóes têm interesse por si só dentro de uma determinada população (abordagem diferencial), sem comparação com um grupo padrão (abordagem comparativa). Neste sentido, o que está se tentando discutir é o viés que o primado da visão pode estar exercendo na percepção de quais são as dificuldades enfrentadas por professores e alunos na aprendizagem de genética em turmas mistas.

Nunes e Lomônaco (2008) esclarecem que indivíduos cegos usam recursos e caminhos diferentes dos videntes para conhecer o mundo que os cerca e que, portanto, a falta da visão não impede o seu desenvolvimento, mas impóe caminhos diferentes por meio de outras vias de acesso. No entanto, os alunos cegos (e é possível dizer aqui: também os videntes e também os professores) apontaram que um ensino baseado em figuras prejudica a sua compreensão dos conceitos genéticos (e é possível dizer aqui no caso dos professores e alunos videntes: restringe a sua apropriação dos conceitos).

Importante para esta discussão sobre a influência do primado da visão no ensino de genética são as idéias do epistemólogo francês Gaston Bachelard. Bachelard, entre as décadas de 1920 e 1930, propôs um conceito muito interessante: a fenomenotécnica (BACHELARD, 1978, 1983). Neste conceito, Bachelard deixava clara a importância da atividade racional sobre a observação dos fenômenos, bem como da sua contraparte material, a técnica. Assim, segundo ele, todas as observações em ciência são, de fato, construções que incorporam de forma ativa 
o real e a razão (SISSON; WINOGRAD, 2012). Neste sentido, ele explicitamente se insurgiu contra o primado da visão que reinava sobre a interpretação da atividade científica e tentou estabelecer, com a sua epistemologia, um primado da mão. A mão ativa, criativa, construtora e não aquela submissa, representacional dos objetos táteis aos quais se tenta submeter os cegos ao primado da visão, como já o são professores e alunos videntes.

\section{Conclusóes}

Neste ponto, é importante tentar sintetizar os argumentos que se tentou desenvolver aqui. Primeiro, acredita-se que a percepção de professores e alunos sobre a aprendizagem de genética em salas de aula mistas é marcada pelo primado da visão que norteia muito do ensino de biologia. Segundo, por motivos óbvios, os alunos cegos não estão todo submetidos a este primado e, portanto, podem oferecer pistas sobre a aprendizagem destes conceitos (o que foge ao escopo deste trabalho). Terceiro, que um ensino de biologia (e genética) para cegos baseado em modelos táteis é a parte dos cegos submetida ao primado da visão. Por fim, que este primado é responsável por uma cegueira epistemológica que obscurece o fato de que o fazer científico tem muito menos de ver e muito mais de fazer/agir sobre o mundo de forma ativa, como tentaria estabelecer Gaston Bachelard.

\section{REFERÊNCIAS}

BACHELARD, G. A epistemologia. 2.ed. Rio de Janeiro: Zahar, 1983.

BACHELARD, G. A filosofia do Não. São Paulo: Abril Cultura, 1978.

BARDIN, L. Análise de conteúdo. Lisboa: Edições 70, 1977.

BARROS, M.M.V.; CARNEIRO, M.H.S. Os conhecimentos que os alunos utilizam para ler as imagens de mitose e de meiose e as dificuldades apresentadas. In: ENCONTRO NACIONAL DE PESQUISA EM EDUCAÇÃO EM CIÊNCIAS, 5., 2005, São Paulo. Atas... Rio de Janeiro: UFRJ, 2005. Disponível em: <http:/www.nutes.ufrj.br/abrapec/venpec/conteudo/artigos/3/pdf/p319.pdf>. Acesso em: 10 jun. 2016.

BATISTA, C.G. Formação de conceitos em crianças cegas: questôes teóricas e implicaçôes educacionais. Psicologia: Teoria e Pesquisa, Brasília, DF, v.21, n.1, p.7-15, 2005.

BRASIL. Declaração de Salamanca e linha de ação sobre necessidades educativas especiais. Brasília, DF: UNESCO, 1994.

BRASIL. Instituto Nacional de Estudos e Pesquisas Educacionais. Censo Escolar da Educação Básica 2013: resumo técnico. Brasília, DF: O Instituto, 2014.

BRASIL. Ministério da Educação. Lei de Diretrizes e Bases da Educação Nacional. LDB 9.394, de 20 de dezembro de 1996.

BRASIL. Ministério da Educação. Secretaria de Educação Especial. Política nacional de educação especial na perspectiva da educação inclusiva. Brasília, DF: MEC/SEESP, 2008.

BRASIL. Ministério da Educação. Secretaria de Educação Especial. Diretrizes nacionais para a educação especial na educação básica. Brasília, DF: MEC/SEESP, 2001. 
CARDINALI, S.M.M.; FERREIRA, A.C. A aprendizagem da célula pelos estudantes cegos utilizando modelos tridimensionais: um desafio ético. Revista Benjamim Constant, Rio de Janeiro, n.46, p.1-10, 2010.

CID, M.; NETO, A.J. Dificuldades de aprendizagem e conhecimento pedagógico do conteúdo: o caso da genética. Enseñanza de las Ciencias, Catalunia, Número Extra, p.1-5, 2005.

CUNHA, E. Práticas pedagógicas para a inclusão e diversidade. 3.ed. Rio de Janeiro: Wak, 2013.

FERREIRA, P.M.P.F. et al. Avaliação da importância de modelos no ensino de biologia através da aplicaçáo de um modelo demonstrativo da junçáo intercelular desmossomo. Revista Brasileira de Biociências, Porto Alegre, v.11, n.4, p.388-394, 2013.

FIGUEIREDO, R.M.E.; KATO, O.M. Estudos nacionais sobre o ensino de cegos: uma revisão bibliográfica. Revista Brasileira de Educação Especial, Marília, v.21, n.4, p.477-488, 2015.

FOGLI, B.F.C.S. A dialética da inclusão em educação: uma possibilidade em um cenário de contradiçóes. Petrópolis: De Petrus et al, 2012.

GASPARETTO, M.E.R.F. et al. Utilização de recursos de tecnologia assistiva por escolares com deficiência visual. Informática na educação: teoria \& prática, Porto Alegre, v.15, n.2, p.113-130, 2012.

GIL, A.C. Métodos e técnicas de pesquisa social. 6.ed. São Paulo: Átlas, 2008.

GLAT, R.; BLANCO, L.M.V. Educação especial no contexto de uma educação inclusiva. In: GLAT, R. (Org.). Educação inclusiva: cultura e cotidiano escolar. Rio de Janeiro: 7 Letras, 2007. p.15-35

GOLDBACH, T. et al. Problemas e desafios para o ensino de genética e temas afins no ensino médio: dos levantamentos aos resultados de um grupo focal. In: ENCONTRO NACIONAL DE PESQUISA EM EDUCAÇÃO E CIÊNCIA, 7., 2009, Florianópolis. Anais eletrônico... Rio de Janeiro: ABRAPEC, 2009. Disponível em: <http://posgrad.fae.ufmg.br/posgrad/viienpec/pdfs/1570.pdf>. Acesso em: 10 jun. 2016.

HECK, C.M.; HERMEL, E.E.S. Análise imagética das células em livros didáticos de biologia do ensino médio. Revista de Ensino de Biologia da Associação Brasileira de Ensino de Biologia (SBEnBio), Niterói, v.7, p.1401-1409, 2014.

KLAUTAU-GUIMARÁES, M.N. et al. Combinar e recombinar com os dominós. Genética na Escola, Ribeirão Preto, v.3, n.2, p.1-7, 2008.

LAPLANE, A.L.F.; BATISTA, C.G. Ver, não ver e aprender: a participação de crianças com baixa visão e cegueira na escola. Caderno Cedes, Campinas, v.28, n.75, p.209-227, 2008.

LEWIS, J.L.J.; WOOD-ROBINSON, C. Chromosomes: the missing link - young people's understanding of mitosis, meiosis, and fertilisation. Journal of Biological Education, Londres, v.34, n.4, p.189-199, 2000.

LOPES, M.C; FABRIS, E.H. Inclusão \& Educação. Belo Horizonte: Autêntica, 2013.

MARÍN, Y.A.O. Aprender sobre herança genética: mais que um quadro de Punnet. In: ENCONTRO NACIONAL DE PESQUISA EM EDUCAÇĀO EM CIÊNCIAS, 9., 2013, Águas de Lindóia. Atas... Rio de Janeiro: UFRJ, 2013. Disponível em: <http://www.nutes.ufrj.br/abrapec/ixenpec/atas/resumos/ R0514-1.pdf>. Acesso em: 10 jun. 2016.

MAZZARINO, J.M.; FALKENBACH, A.; RISSI, S. Acessibilidade e inclusão de uma aluna com deficiência visual na escola e na educação física. Revista Brasileira de Ciências e Esporte, Porto Alegre, v.33, n.1, p.87-102, 2011. 
MOURA, J. et al. O ensino de biologia, com enfoque na genética, das escolas públicas do Brasil breve relato e reflexão. Semina: Ciências Biológicas e da Saúde, Londrina, v.34, n.2, p.167-174, 2013.

NUNES, S.S.; LOMÔNACO, J.F.B. Desenvolvimento de conceitos em cegos congênitos: caminhos de aquisição do conhecimento. Revista Semestral da Associação Brasileira de Psicologia Escolar e Educacional, São Paulo, v.12, n.1, p.119-138, 2008.

PERALES, F.J.; JIMÉNEZ, J.D. Las ilustraciones en la enseñanza, aprendizaje de las ciências: Análisis del libro texto. Enseñanza de las Ciencias, Barcelona, v.20, n.3, p.369-386, 2002.

PETROVICH, A.C. et al. Temas de difícil ensino e aprendizagem em ciências e biologia: experiências de professores em formação durante o período de regência. Revista de Ensino de Biologia da Associação Brasileira de Ensino de Biologia (SBEnBio), Niterói, v.7, p.363-373, 2014.

PLETSCH, M.D. Educação especial e inclusão escolar: políticas, práticas curriculares e processos de ensino e aprendizagem. Poiesis Pedagógicas, Goiás, v.12, n.1, p.7-26, 2014.

REGIANI, A.M.; MÓL, G.S. Inclusão de uma aluna cega em um curso de licenciatura em química. Ciência \& Educação, São Paulo, v.19, n.1, p.123-134, 2013.

SANTOS, C.R.; MANGA, V.P.B.B. Deficiência visual e ensino de biologia: pressupostos inclusivos. Revista Cientifica da Faculdade Cenecista de Vila Velha, Vila Velha, n.13, p.13-22, 2009.

SANTOS, L. A epistemologia genética: redescobrindo seu conceito evolucionista e estruturalista através da educação especial. In: CONGRESSO DE EPISTEMOLOGIA GENÉTICA DA REGIÃO AMAZÔNICA, 1., 2011, Rondônia. Anais... Amazônia: UNIR, 2011. Disponível em: <http://www. periodicos.unir.br/index.php/revistacegra/article/view/276>. Acesso em: 10 jun. 2016.

SANTOS, S. Para geneticistas e educadores: o conhecimento cotidiano sobre a herança biológica. São Paulo: Annablume, 2005.

SILVA, A.P.Z. et al. História da ciência e ensino da genética: uma análise dos anais dos VII e VIII encontros nacionais do ensino de ciências. Revista de Ensino de Biologia da Associação Brasileira de Ensino de Biologia (SBEnBio), Niterói, n.7, p.517-529, 2014.

SISSON, N.; WINOGRAD, M. Bachelard e Freud: fenomenotécnica e psicanálise. Arquivos Brasileiros de Psicologia, Rio de Janeiro, v.64, n.3, p.146-162, 2012.

SOLHA, G.C.F.; SILVA, E.P. Onde está o lugar do conceito de gene? Episteme, Porto Alegre, v.19, p.45-68, 2004.

TIDON, R.; LEWONTIN, R.C. Teaching evolutionary biology. Genetics and Molecular Biology, Ribeirão Preto, v.27, n.1, p.124-131, 2004.

Recebido em: 15/06/2016

Reformulado em: 21/10/2016

Aprovado em: 21/10/2016 